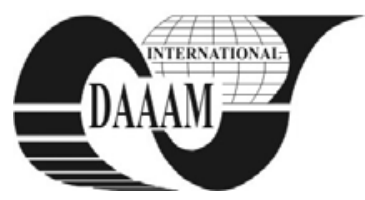

Annals of DAAAM for 2011 \& Proceedings of the 22nd International DAAAM Symposium, Volume 22, No. 1, ISSN 1726-9679 ISBN 978-3-901509-83-4, Editor B. Katalinic, Published by DAAAM International, Vienna, Austria, EU, 2011 Make Harmony between Technology and Nature, and Your Mind will Fly Free as a Bird Annals \& Proceedings of DAAAM International 2011

\title{
RHEOLOGICAL BEHAVIOUR OF WHEAT FLOUR DOUGH DURING MIXING AND HEATING
}

\author{
MIRONEASA, S[ilvia]; GUTT, S[onia]; GUTT, G[heorghe] \& CODINA, G[eorgiana] - G[abriela]
}

\begin{abstract}
The aim of this study was to determine the possibility of using Mixolab to assess the quality of different types of wheat flour dough. The Mixolab data was compared to various flour quality characteristics chosen to represent a wide range in terms of technological quality. The results obtained for the analytical and Mixolab rheological characteristics of flour samples were examined by multivariate data analysis, using principal component analysis (PCA). Our results indicated strong relationships in terms of gluten deformation index and falling number index with almost all of the rheological parameters used to evaluate a Mixolab curve.
\end{abstract}

Key words: mixolab parameters, rheological properties, multivariate analysis

\section{INTRODUCTION}

Bread dough is a viscoelastic material strongly related to the gluten proteins responsible for the different qualities of wheat flour dough. In the baking industry, many rheological instruments have been developed to characterize the viscoelasticity properties of dough and further to predict the quality of the final products (e.g., Alveograph, Consistograph, Amylograph, Extensigraph, Farinograph, Mixograph, Maturograph). Some of these traditional instruments record dough consistency during kneading and others record paste viscosity during cooking-cooling cycles. However, both of these characteristics can be recorded only with the most recent Chopin Mixolab (Tripette\&Renault France) device which measures the torque of the dough during an increase in temperature in a single test with less than 100 grams of sample. Information about Mixolab parameters was reported by Collar et al. (2007), Kahrman et al. (2008), Ozturk et al. (2008), Banu et al. (2010), Codină et al. (2010), Rosell et al. (2010). Because the optimal parameters established by this device have not been completely finished, we thought it would be useful if we tried to establish a series of correlations between the technological parameters of a range of Romanian white wheat flour and the Mixolab parameters curve by using multivariate analysis.

\section{EXPERIMENTAL RESEARCH}

Thirty samples of different commercial wheat flours were obtained from different milling companies. The analytical parameters of the samples (Table 1) were determined according to the approved method of ICC or Romanian standard methods: moisture content (ICC Standard No. 110/1), protein content (ICC Standard No. 202), wet gluten content (ICC Standard No. 106/1), gluten deformation index (SR No. 90), ash content (ICC No 104/1) and falling number index (ICC No. 107/1). The rheological properties of wheat flour dough were determined by Mixolab device using "Chopin+" protocol (Tab. 2), according to the international standard (ICC-Standard Method No. 173, 2008). All the measurements were done in triplicates and inserted in the database. The values of the parameters are expressed as \pm standard deviation to a confidence interval of $95 \%$.

The correlation coefficients between the technological characteristics of wheat flour dough and the Mixolab parameters curve was analyzed using Principal Component Analysis (PCA). The first two principal components (PCs) explain $99.86 \%$ of the total variance $(\mathrm{PC} 1=99.73 \%$ and PC1 $=0.13 \%$ ), Figure 1 . Regarding the first component PC1, one can notice that there is a very good correlation between the parameters falling number index (FN), cooking stability (C4), starch gelling (C5 and C54) and protein content (PR). These parameters are strongly associated with the first component PC1. The second principal component, PC2 distinguishes the parameters stability (ST) and the gluten deformation index (GDI), which are opposed. Stability (ST) and water absorption $(\mathrm{CH})$ are well correlated $(\mathrm{r}=0.507)$. In regard to the second principal component PC2, the parameters stability (ST), maximum consistency during phase 1 (C1), moisture content (MO), the difference between the points $\mathrm{C} 1$ and $\mathrm{C} 2$ (C12) and gluten deformation index (GDI) are placed on the left of the graph, which shows that these contribute to a larger extent to the evaluation of dough in comparison to the variables on the right. The plot of PC1 vs. PC2 loadings shows, along the PC1 component, a close association between the FN and Mixolab parameters curve, form stages four and five (C4, C5, and C54). The closeness of MO to the centre of the PC shows that this parameter is not useful to describe the rheological behaviour of wheat flour dough. According to the position in the PC space of parameters analyzed, the largest contributions to the rheological properties of the Mixolab curve have been recorded for the parameters FN and GDI.

There are certain significant correlations established between the technological parameters of flours. For instance, protein content is significantly $(p=0.05)$ positive, correlated with the wet gluten content $(r=0.406)$ and highly significant ( $p$ $=0.01)$ with the FN index $(r=0.636)$. So, in cereal richer in proteins, amylolytic activity decreases.

\begin{tabular}{|c|c|c|c|c|c|}
\hline \multirow{2}{*}{ Parameters } & \multirow{2}{*}{$\begin{array}{c}\text { Abbreviate } \\
\text { name }\end{array}$} & \multirow{2}{*}{ Mean } & \multicolumn{2}{|c|}{ Range } & \multirow{2}{*}{ Std. dev. } \\
\hline & & & min. & max. & \\
\hline $\begin{array}{l}\text { Moisture } \\
\text { content (\%) }\end{array}$ & MO & 14.30 & 12.50 & 15.20 & 0.77 \\
\hline $\begin{array}{l}\text { Protein } \\
\text { content (\%) }\end{array}$ & PR & 14.28 & 9.50 & 16.20 & 1.79 \\
\hline $\begin{array}{l}\text { Wet gluten } \\
\text { content (\%) }\end{array}$ & WG & 26.72 & 23.60 & 30.00 & 1.64 \\
\hline $\begin{array}{l}\text { Gluten } \\
\text { deformation } \\
\text { index (mm) }\end{array}$ & GDI & 6.34 & 3.00 & 14.00 & 2.56 \\
\hline $\begin{array}{l}\text { Ash content } \\
\text { (\%) }\end{array}$ & Ash & 0,65 & 0.62 & 0.68 & \\
\hline $\begin{array}{l}\text { Falling } \\
\text { Number } \\
\text { index (s) }\end{array}$ & FN & 387.60 & 198.00 & 485.00 & 81.98 \\
\hline
\end{tabular}

Tab. 1. Flour analytical parameters 


\begin{tabular}{|c|c|c|c|c|c|}
\hline \multirow{2}{*}{ Parameters } & \multirow{2}{*}{$\begin{array}{c}\text { Abbreviate } \\
\text { name }\end{array}$} & \multirow{2}{*}{ Mean } & \multicolumn{2}{|c|}{ Range } & \multirow{2}{*}{$\begin{array}{l}\text { Std. } \\
\text { dev. }\end{array}$} \\
\hline & & & min. & $\max$. & \\
\hline $\begin{array}{l}\text { Water absorption } \\
\text { (\%) }\end{array}$ & $\mathrm{CH}$ & 57.98 & 53.80 & 61.20 & 1.62 \\
\hline $\begin{array}{l}\text { Development time } \\
\text { (min) }\end{array}$ & DT & 2.27 & 1.08 & 5.24 & 1.28 \\
\hline Stability (\%) & ST & 8.40 & 5.00 & 10.46 & 1.25 \\
\hline $\begin{array}{l}\text { Maximum } \\
\text { consistency during } \\
\text { - stage } 1(\mathrm{~N} \cdot \mathrm{m})\end{array}$ & $\mathrm{C} 1$ & 1.09 & 0.99 & 1.22 & 0.04 \\
\hline - stage $2(\mathrm{~N} \cdot \mathrm{m})$ & $\mathrm{C} 2$ & 0.43 & 0.35 & 0.54 & 0.041 \\
\hline - stage $3(\mathrm{~N} \cdot \mathrm{m})$ & $\mathrm{C} 3$ & 1.83 & 1.40 & 2.21 & 0.221 \\
\hline - stage $4(\mathrm{~N} \cdot \mathrm{m})$ & C4 & 1.56 & 0.97 & 1.98 & 0.26 \\
\hline - stage $5(\mathrm{~N} \cdot \mathrm{m})$ & $\mathrm{C} 5$ & 2.34 & 1.31 & 3.18 & 0.53 \\
\hline $\begin{array}{l}\text { Difference of the } \\
\text { points } \\
\text { C1 - C2 }(\mathrm{N} \cdot \mathrm{m})\end{array}$ & $\mathrm{C} 12$ & 0.66 & 0.58 & 0.79 & 0.05 \\
\hline C3 - C2 (N·m) & $\mathrm{C} 32$ & 1.39 & 1.00 & 1.78 & 0.20 \\
\hline $\mathrm{C} 5-\mathrm{C} 4(\mathrm{~N} \cdot \mathrm{m})$ & $\mathrm{C} 54$ & 0.79 & 0.28 & 1.46 & 0.31 \\
\hline
\end{tabular}

Tab. 2. Mixolab parameters of flour samples

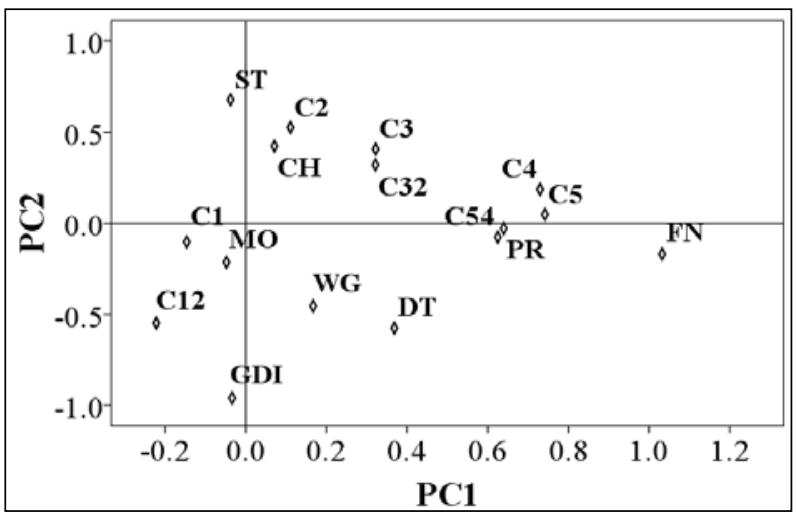

Fig. 1. PC1 and PC2 score for the Mixolab rheological parameters and analytical characteristics (moisture content, protein content, wet gluten content, gluten deformation index and falling number index)

This is due to the deactivation of alpha-amylase which is retained by glutenine in quantities that become larger as glutenine becomes larger. These results are in agreement with those obtained by Codină et al. (2010).

The quality of the proteins is given by the wet gluten content and gluten deformation index. The gluten deformation index is given by the capacity of wet gluten to extend when it is left in a rest time period. The gluten deformation is higher when the proteolytic activity of the flour increases. Therefore, inverse high correlations were obtained at level of significance $p=0.01$ between the parameter GDI and the Mixolab parameters curve: ST $(r=-0.500)$, C2 $(r=-0.534)$, C3 $(r=-0.536)$ and at significance level $\mathrm{p}=0.05$ with $\mathrm{C} 4(\mathrm{r}=-0.402)$ and C32 $(\mathrm{r}=-$ $0.458)$. GDI shows a positive effect on $\mathrm{C} 12(\mathrm{r}=0.502, \mathrm{p}=$ $0.01)$ and DT $(r=0.405, \mathrm{p}=0.05)$.

Regarding the correlations of the parameter FN index with the parameters of the Mixolab curve, there were obtained correlations of strong significance $(p=0.01)$ in terms of starch characteristics: C4 $(r=0.734)$, C5 $(r=0.737)$, C54 $(r=0.618)$ and of a moderate association significance with C3 $(r=0.390)$, C32 $(r=0.382)$. These results are in concordance with those obtained by Codină et al. (2010).

The Mixolab allows recording the mechanical changes due to mixing and heating, thus simulating the mechanical work in five stages. During stage one, the temperature of $30^{\circ} \mathrm{C}$ is kept for 8 minutes to ensure that the dough is prepared and weakening takes place during this phase. Stage two (protein weakening) corresponds to the first stage of dough warming. The increase in dough temperature in the Mixolab implies the protein denaturation involving the release of a large quantity of water content. Within the temperature range of stage two, the proteolytic enzymes have an optimal activity, represented in the Mixolab curve by the difference between the points $\mathrm{C} 1$ and $\mathrm{C} 2$. That way, the Mixolab parameters curve from this stage was the best correlated with the wet deformation content. Stage three corresponds to the second stage of dough warming, when its temperature exceeds $50 \div 55^{\circ} \mathrm{C}$. The granules absorb the water available in the content and they swell, so the viscosity increases. During stage four we have a reduction in the viscosity because of the alpha-amylolytic activity. During the fifth stage, starch gelling is achieved during the cooling of the dough and dough consistency increases up to C5 torque. Because of the temperature range of stages three, four and five of the Mixolab curve we can estimate the falling number index (flour alpha-amylase activity) with the parameters values of these stages, the best correlation being obtained especially with the fourth and fifth Mixolab parameters curve. Because flours with high proteolytic activity generally also have high alpha-amylase activity, we obtained a good correlation between the gluten deformation flour index and the Mixolab parameters curve of the last three stages (especially from stages three and four).

\section{CONCLUSIONS}

The comparison between the technological parameters that indicate flour quality (moisture, protein, wet gluten content, gluten deformation index and falling number index) and Mixolab (used with "Chopin+" protocol), using principal component analysis, has shown a good correlation in terms of gluten deformation and falling number index with the Mixolab parameters curve. Therefore, the gluten deformation index presented a good correlation with the development time, stability and the Mixolab parameters curve corresponding to protein weakening ( $\mathrm{C} 2$, difference of the points $\mathrm{C} 1$ and $\mathrm{C} 2)$, starch gelatinization (C3) and amylolytic activity (C4). Regarding the falling number index, we noticed a strong correlation especially with the Mixolab parameters curve corresponding to starch gelling (C5, difference of the points $\mathrm{C5}$ and C4).

In our further studies, we want to establish predictive models for estimating the values of the analytical parameters of wheat flour based on the Mixolab rheological parameters curve. We consider that these future studies will be extremely useful for the workers in baking industry and not only.

\section{REFERENCES}

Banu, I., Stoenescu, G., Ionescu, V. \& Aprodu, I. (2010). Physicochemical and Rheological Analysis of Flour Mill Streams, Cereal Chemistry, No. 87, 112-117, ISSN 0009-0352

Codină, G.G., Mironeasa, S., Bordei, D. \& Leahu, A. (2010). Mixolab versus Alveograph and Falling Number, Czech $J$. of Food Sciences, No. 28, 185-191, ISSN 1212-1800

Collar, C., Bollaín, C. \& Rosell, C.M. (2007). Rheological behaviour of formulated bread doughs during mixing and heating, Food Science and Technology International, No. 13, 99-107, ISSN 1082-0132

Kahraman, K., Sakiyan, O., Ozturk, S., Koksel, H., Sumnu, G. \& Dubat, A. (2008). Utilization of Mixolab to predict the suitability of flours in terms of cake quality, European Food Research and Technology, No. 227, 565-570, ISSN 1438-2377

Ozturk, S., Kahrman, K., Tiftick, B. \& Koksel, H. (2008). Predicting the cookie quality of flours by using Mixolab, European Food Research and Technology, No. 227, 14591554, ISSN 1438-2377

Rosell, C.M., Santos, E. \& Collar, C. (2010). Physical characterisation of fiber-enriched bread doughs by dual mixing and temperature constraint using the Mixolab, Eur Food Res Technol, No. 231, 535-544, ISSN 1438-2377 